\title{
Final Report: Use of Graphite Foam as a Thermal Performance Enhancement for Heavy Hybrid Propulsion Systems
}

January 29, 2007

Prepared by

James W. Klett

Materials Science \& Technology Division 
This report was prepared as an account of work sponsored by an agency of the United States Government. Neither the United States Government nor any agency thereof, nor any of their employees, makes any warranty, express or implied, or assumes any legal liability or responsibility for the accuracy, completeness, or usefulness of any information, apparatus, product, or process disclosed, or represents that its use would not infringe privately owned rights. Reference herein to any specific commercial product, process, or service by trade name, trademark, manufacturer, or otherwise, does not necessarily constitute or imply its endorsement, recommendation, or favoring by the United States Government or any agency thereof. The views and opinions of authors expressed herein do not necessarily state or reflect those of the United States Government or any agency thereof. 
ORNL/TM-2007/008

FINAL REPORT: USE OF GRAPHITE FOAM AS A THERMAL PERFORMANCE ENHANCEMENT FOR HEAVY HYBRID PROPULSION SYSTEMS

James W. Klett and Jim Conklin

Oak Ridge National Laboratory

Oak Ridge, Tennessee 37831-6087

January 29, 2007

DOE Project No. 1969-T235-06

Prepared for

Jenifer Hitchcock

U.S. Army Tank-Automotive and Armaments Command

Warren, MI 48071

Phone: (586) 574-6411

Fax: (586) 574-6280

hitchcoj@tacom.army.mil

\author{
Prepared by \\ OAK RIDGE NATIONAL LABORATORY \\ P.O. Box 2008 \\ Oak Ridge, Tennessee 37831-6283 \\ managed by \\ UT-Battelle, LLC \\ for the \\ U.S. DEPARTMENT OF ENERGY \\ under contract DE-AC05-00OR22725
}





\section{CONTENTS}

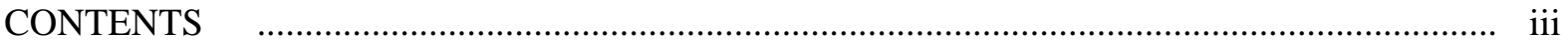

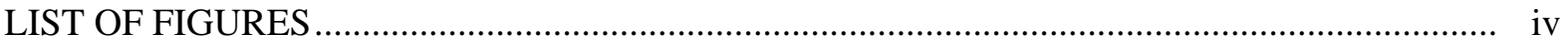

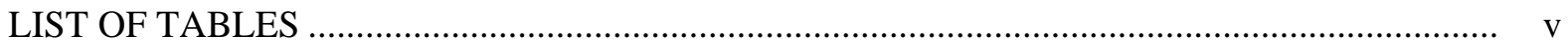

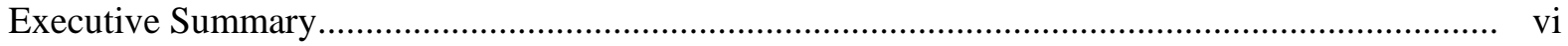

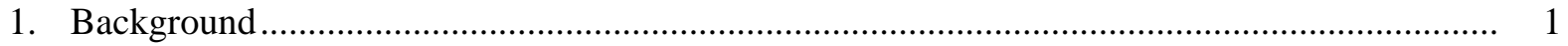

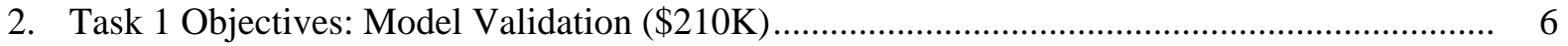

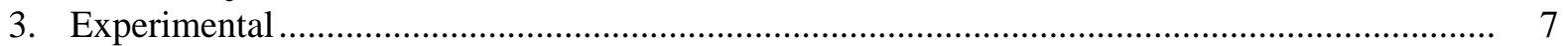

3.1 Task 1-A.: Permeability and Heat-Transfer Parameter Measurement ................................. 7

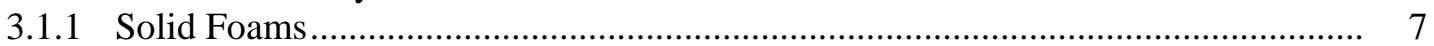

3.1.2 Finned Foam Parameters ................................................................................ 9

3.2 Modeling Development and Validation...................................................................... 9

3.2.1 New Model Development ............................................................................. 9

3.2.2 New Model Validation .......................................................................... 9

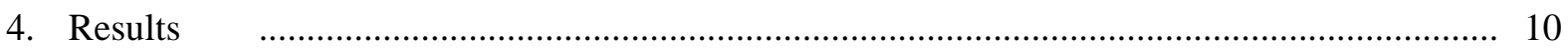

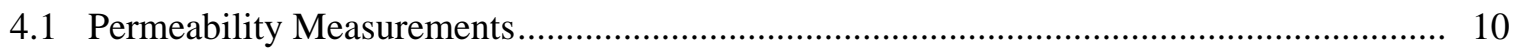

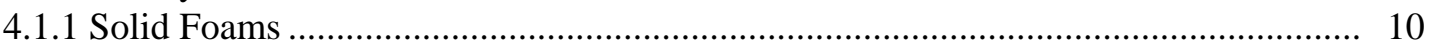

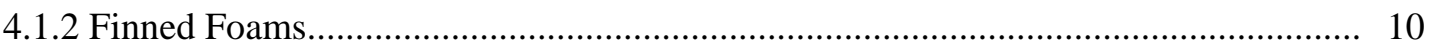

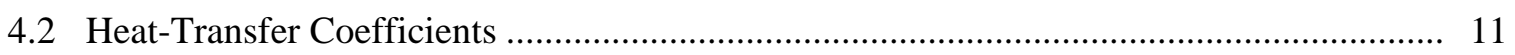

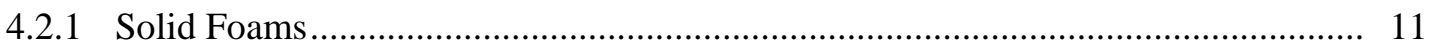

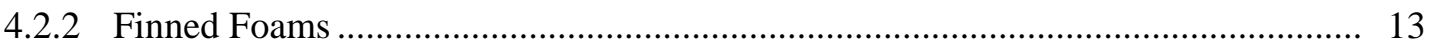

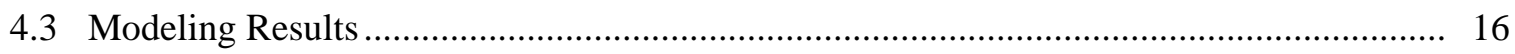

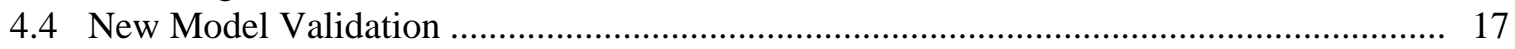

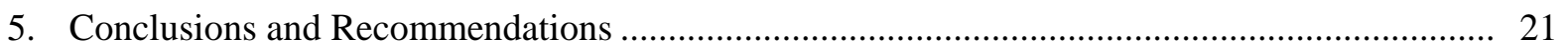

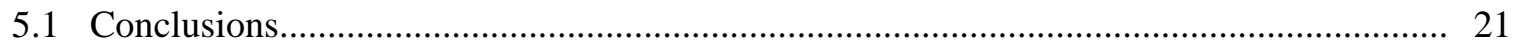

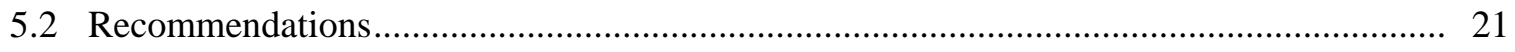

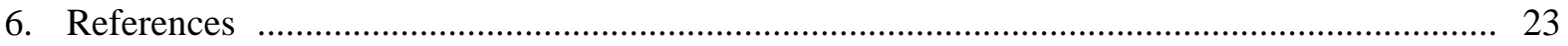




\section{LIST OF FIGURES}

$\begin{array}{lll}\text { Figure } & \text { Page }\end{array}$

Fig. 1. Cold plate data showing lower pumping powers required for same thermal resistance with corrugated foams than the power required for conventional folded-fin aluminum cold plates. 2

Fig. 2. Model of fluid flow and heat transfer through grapfhite foam using FLOW3D. .................... 3

Fig. 3. Air foil designs of heat exchangers. The foam air foil heat exchangers have less drag than standard heat exchangers, but reject the same heat. .......................................................... 4

Fig. 4. Heat rejected by graphite air foil heat exchangers vs standard Visteon core..................... 5

Fig. 5. Experimental apparatus to determine thermal resistance and permeability. ...................... 7

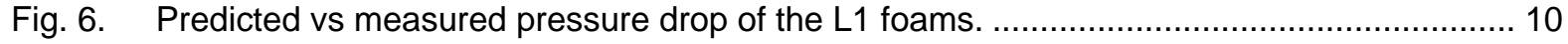

Fig. 7. The $\mathrm{j}$ and $\mathrm{f}$ factors vs Reynolds number for the solid foams. ......................................... 11

Fig. 8. Ratio of $\mathrm{j}$ to $\mathrm{f}$ for the solid foams as a function of Reynolds number................................ 12

Fig. 9. Effect of corrugations on the heat-transfer characteristics of foams. ............................... 12

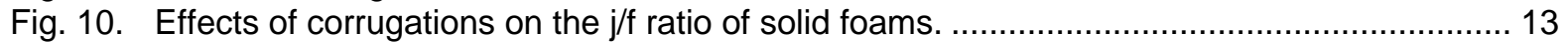

Fig. 11. The $f$ and $\mathrm{j}$ factors for the finned foams vs Reynolds number...................................... 14

Fig. 12. Ratio of $\mathrm{j}$ to $\mathrm{f}$ for finned foams with constant fin thickness vs Reynolds number.................. 14

Fig. 13. Plot of the $\mathrm{j}$ factor and the f factor of measured heat sinks with the graphite foam............... 15

Fig. 14. Ratio of the $\mathrm{j}$ factor to the f factor vs the Reynolds number.......................................... 16

Fig. 15. Model results of the foam in the solid configuration. ..................................................... 17

Fig. 16. Model heat sink to be used with FLOW3D CFD program........................................... 18

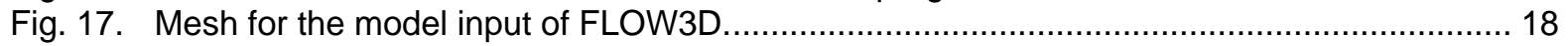

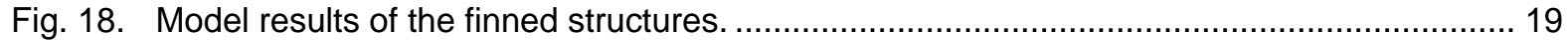

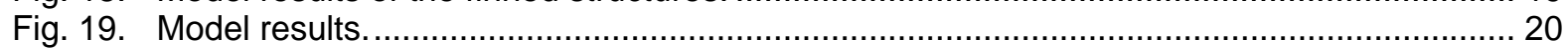

Fig. 20. Conceptual design with graphite foam in a corrugated array that forces air through the pores of the foam. A standard design would involve a filter in line with this heat exchanger to prevent fouling.

Fig. 21. Concept that uses airfoils with tubes to provide increased surface area and reduced pressure drops. The airfoil also protects the part of the foam through which air passes from the heavy particles in the air, thus minimizing fouling of the heat-transfer surface area....... 22 


\section{LIST OF TABLES}

Table

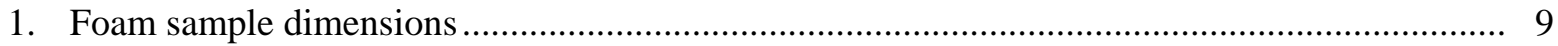

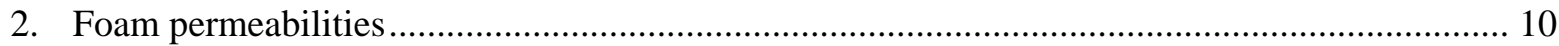

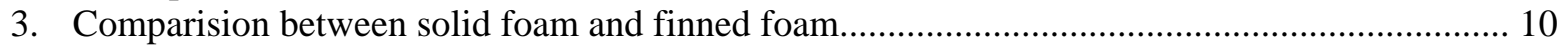

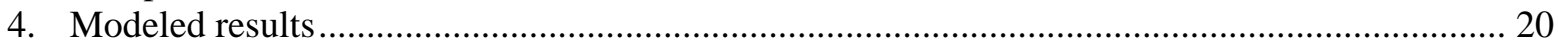




\section{EXECUTIVE SUMMARY}

Oak Ridge National Laboratory's graphite foam has the potential to be used as a heat exchanger for the Army's Future Combat System Manned Ground Vehicle and thus has the potential to improve its thermal performance. The computational fluid dynamics (CFD) program FLOW3D was used to develop a new CFD model for the graphite foam to be used in the development of a proper heat exchanger. The program was calibrated by first measuring the properties of the solid foams and determining the parameters to be used in the CFD model. Then the model was used to predict within $5 \%$ error the performance of finned foam heat sinks. In addition, the $\mathrm{f}$ factors and $\mathrm{j}$ factors commonly used to predict pressure drop and heat transfer were calculated for both the solid and finned structures. There was some evidence that corrugating the foams would yield higher $\mathrm{j} / \mathrm{f}$ ratios than state of the art heat exchangers, confirming previously measured data. Because the results show that the CFD model was validated, it is recommended that the funding for Phases 2 through 5 be approved for the design of both the finned heat exchanger using tubes and round fin structures and the solid foam design using corrugated foams. 


\section{BACKGROUND}

High-thermal-conductivity graphite foam is a mesophase pitch-derived foam with an open cell structure. The foam has cell walls with a highly aligned graphitic arrangement and a density of only $0.5 \mathrm{~kg} / \mathrm{m}^{3}$. This structure exhibits high bulk thermal conductivities $>100 \mathrm{~W} / \mathrm{m} \bullet \mathrm{K}$. This high bulk thermal conductivity at low density results from the foam ligaments having a thermal conductivity $>1750 \mathrm{~W} / \mathrm{m} \bullet \mathrm{K}$. The graphite foam high bulk thermal conductivity is similar to that of aluminum 6061 , which has a density $>2700 \mathrm{~kg} / \mathrm{m}^{3}$. Aluminum is currently the material of choice for commercially available automotive radiators and coolers. Thus, substantial weight savings are possible with graphite foam if the heat-transfer characteristics are at least as good as those of conventional aluminum designs. The further advantages of decreased size and weight are possible if the thermal performance of the graphite foam is greater. The potential for improved thermal performance of the graphite foam may result from appropriate research into the design of its macroscopic and microscopic structure.

Graphite foam has been shown to be an excellent heat-transfer medium for a limited number of applications, including as an extended surface for heat exchangers. Through proper design, it is possible to access most of the surface area inside the foam without a significant increase in pressure drop. For example, in one test, corrugated foam used in a cold plate was shown to exhibit a significantly lower pumping power at the same thermal resistance (Figs. 1 and 2). In another test, a graphite foam airfoil heat exchanger demonstrated the same heat rejection as a commercially available heat exchanger but with significantly less parasitic drag (Figs. 3 and 4). However, these were single-point tests specific to particular applications only and were for systems much smaller than the U.S. Army's Future Combat System Manned Ground Vehicle. Thus in the absence of generally applicable thermal performance correlations, the foam must be engineered to the specific application to maximize heat transfer while minimizing parasitic pressure losses. 
Foam HX
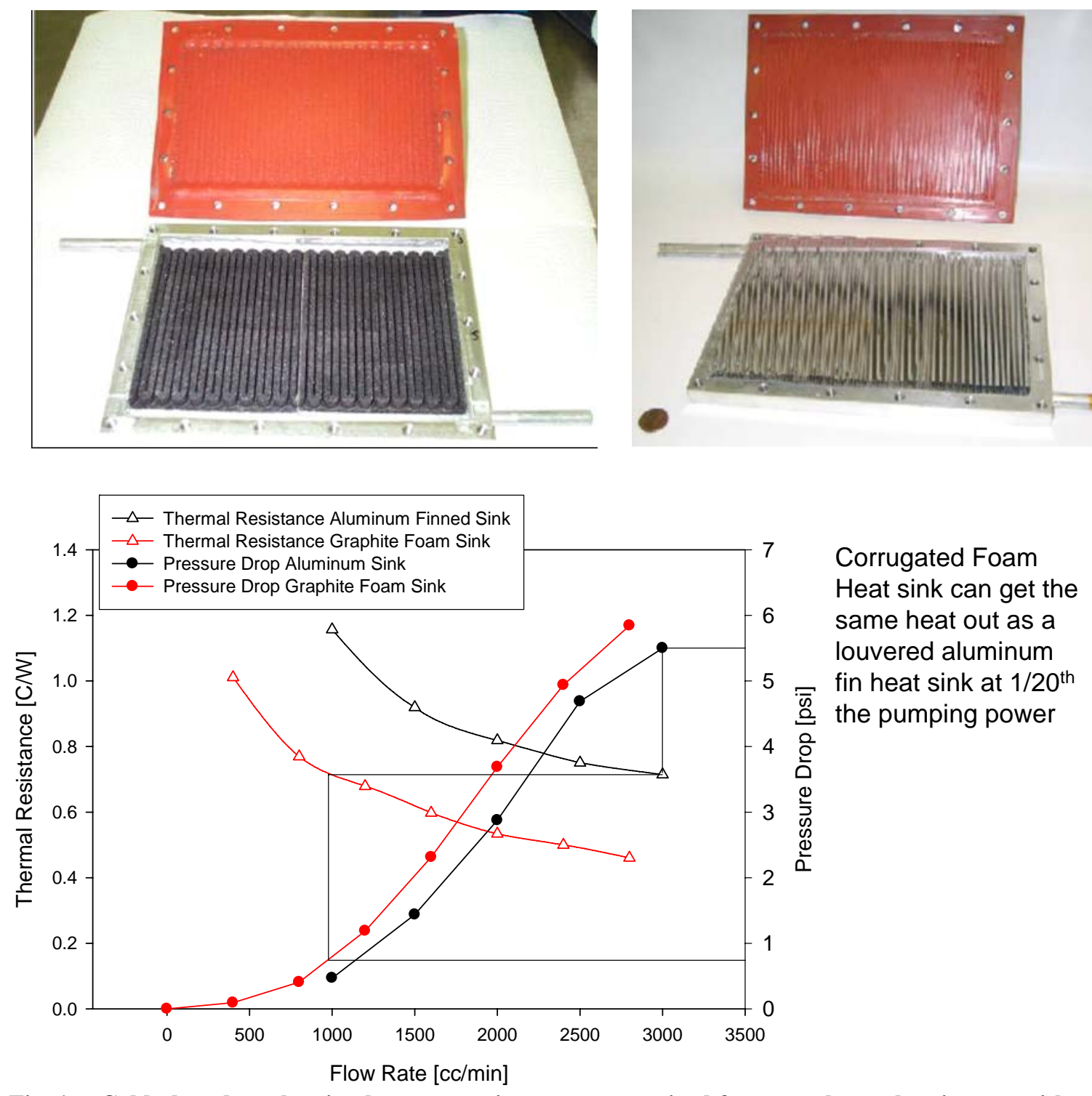

Aluminum $\mathrm{HX}$

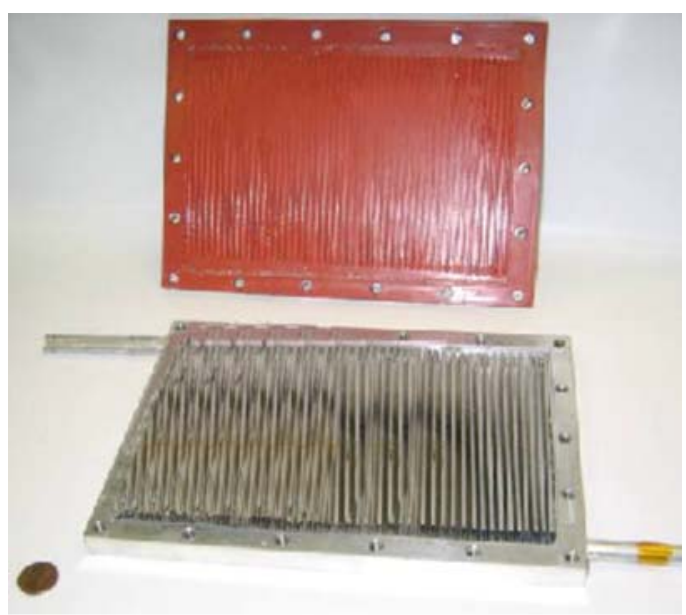




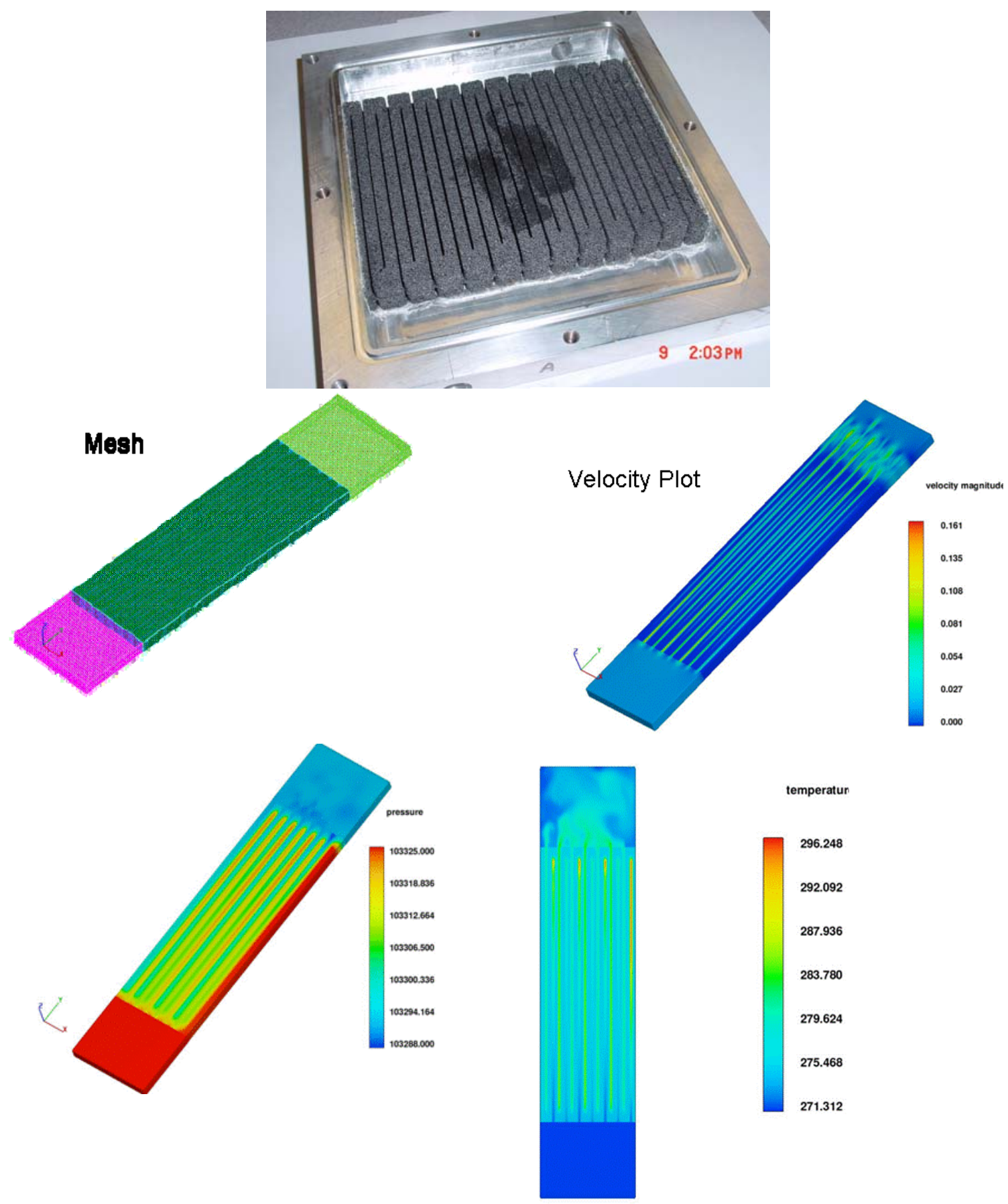

Fig. 2. Model of fluid flow and heat transfer through grapfhite foam using FLOW3D. 

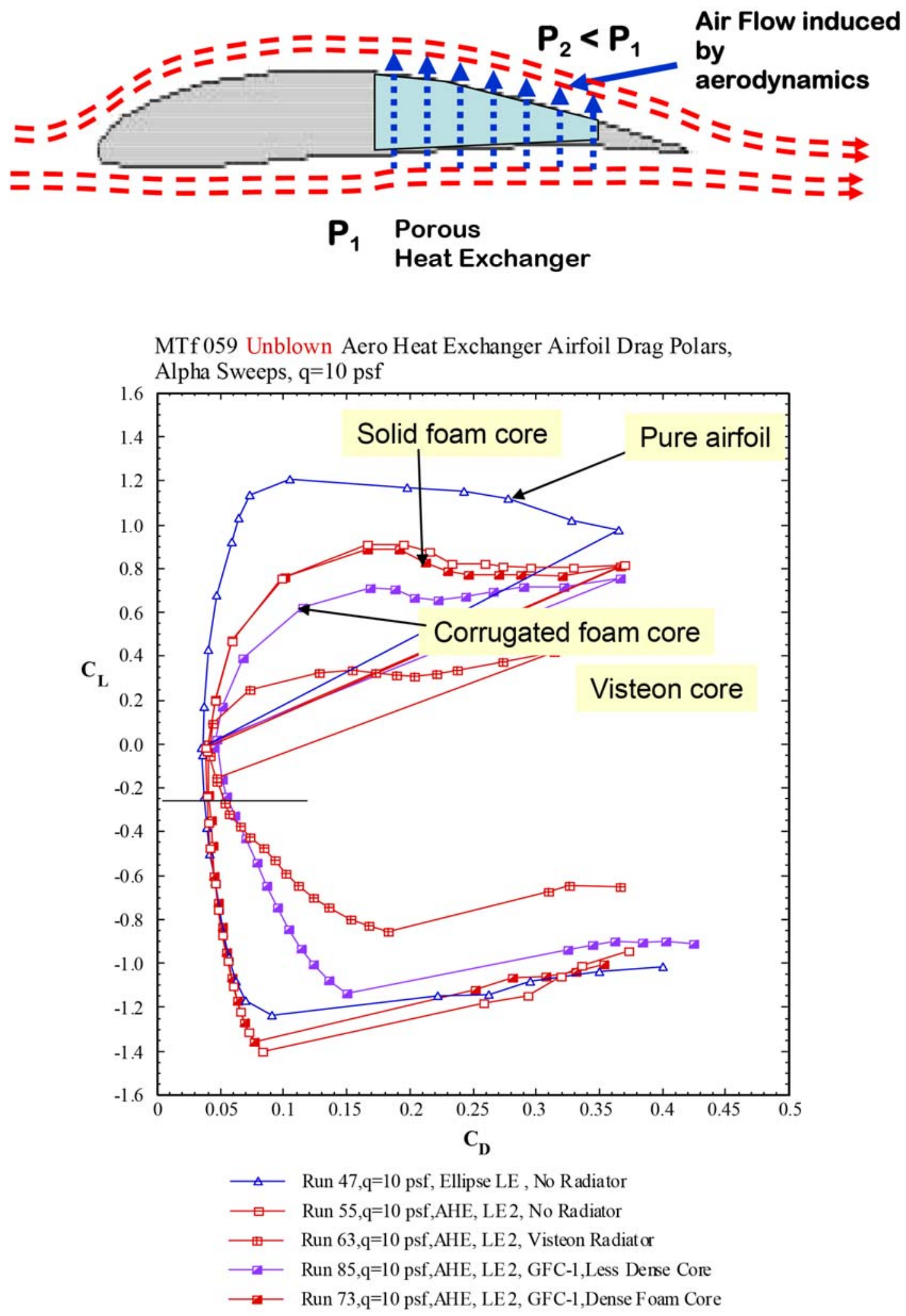

Fig. 3. Air foil designs of heat exchangers. The foam air foil heat exchangers have less drag than standard heat exchangers, but reject the same heat. 


\section{Coolant Flow Rate $\sim 15.5 \mathrm{gal} / \mathrm{min} ; \mathrm{V} \quad$ o $=64 \mathrm{mph}$}

[Test: MTF059]

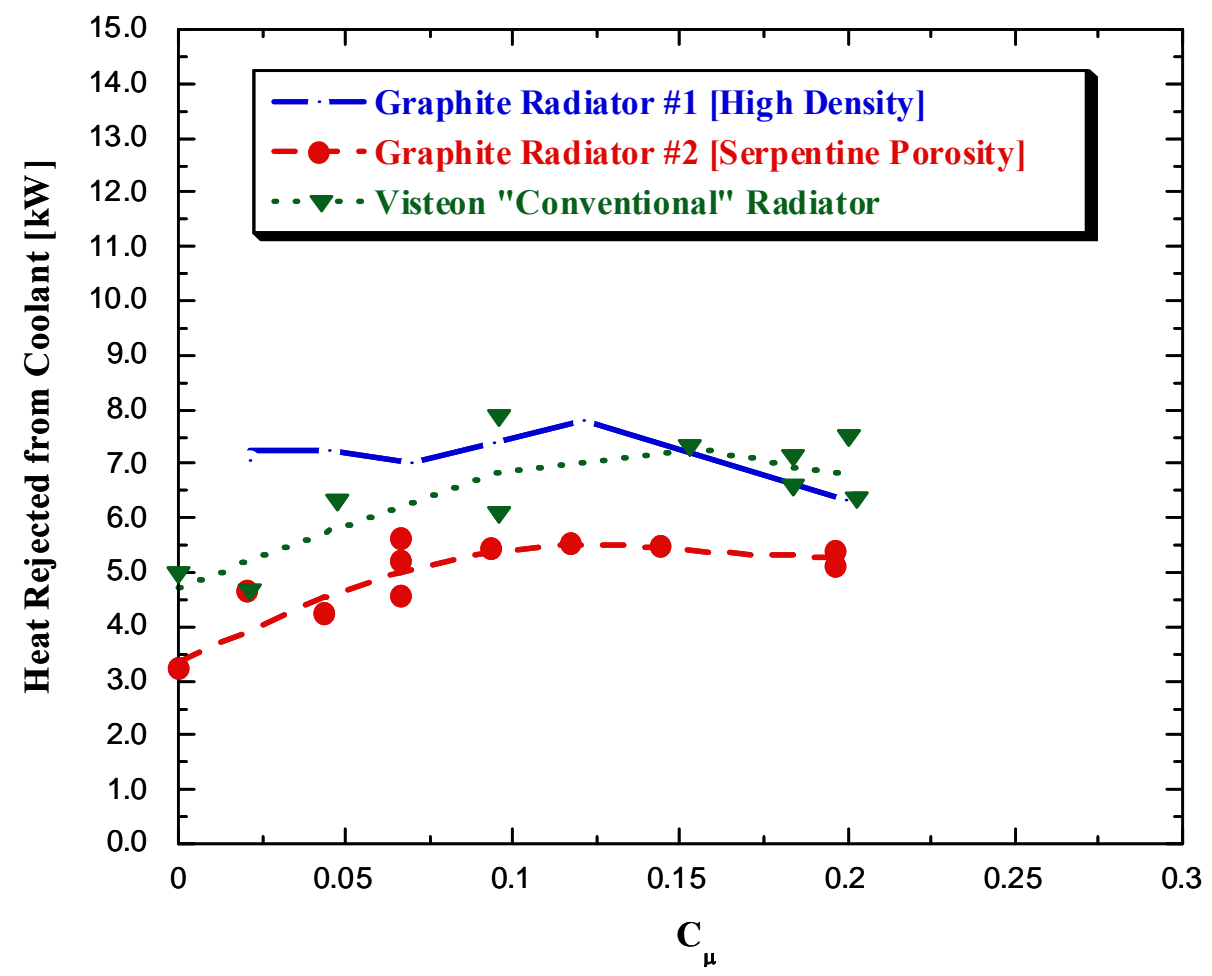

Fig. 4. Heat rejected by graphite air foil heat exchangers vs standard Visteon core. 


\section{TASK 1 OBJECTIVES: MODEL VALIDATION (\$210K)}

The Task 1 objectives of the four subtasks are as follows.

A. Oak Ridge National Laboratory (ORNL) (the contractor) machined 26 samples measuring $2 \times 2 \times 0.25 \mathrm{in}$. for subscale testing. These foams consisted of commercial Kfoam ${ }^{\circledR} \mathrm{L} 1$ and a new foam developed at ORNL that has the potential for higher permeability, higher heat transfer, and higher strengths.

B. ORNL will begin computational fluid dynamics (CFD) modeling of solid foam air tests with the FLOW3D program.

C. ORNL will measure the pressure drop, permeability, and thermal resistance of the 26 samples over an appropriate range of flow conditions.

D. ORNL will compare the results from the CFD modeling with the measured data and will validate the modeling. 


\section{EXPERIMENTAL}

\subsection{TASK 1-A: PERMEABILITY AND HEAT-TRANSFER PARAMETER MEASUREMENT}

\subsubsection{Solid Foams}

The thermal resistance and permeability of two foams were measured. To measure the thermal resistances of these various bonds, standard L1 graphite foam (Koppers K-foam ${ }^{\circledR}$ L1) and an experimental version of L1 foam made at ORNL were chosen. The foam samples were machined into $0.25 \times 2.1 \times 2.0 \mathrm{in}$. samples and were measured for pressure drop vs flow rate and thermal resistance (Fig. 5). Air was passed through the foam at three velocities, and the heat-transfer characteristics were measured. In addition, the pressure drop was measured as a function of flow rate over the range of 0 to $300 \mathrm{lpm}$ and was used to calculate the permeability (from Eq. [1]). From the permeability, the form drag coefficients (A and B) for the FLOW3D program were calculated (from Eq. [2]). The $\mathrm{j}$ factors and $\mathrm{f}$ factors could also be calculated (from Eqs. [3] and [4]).

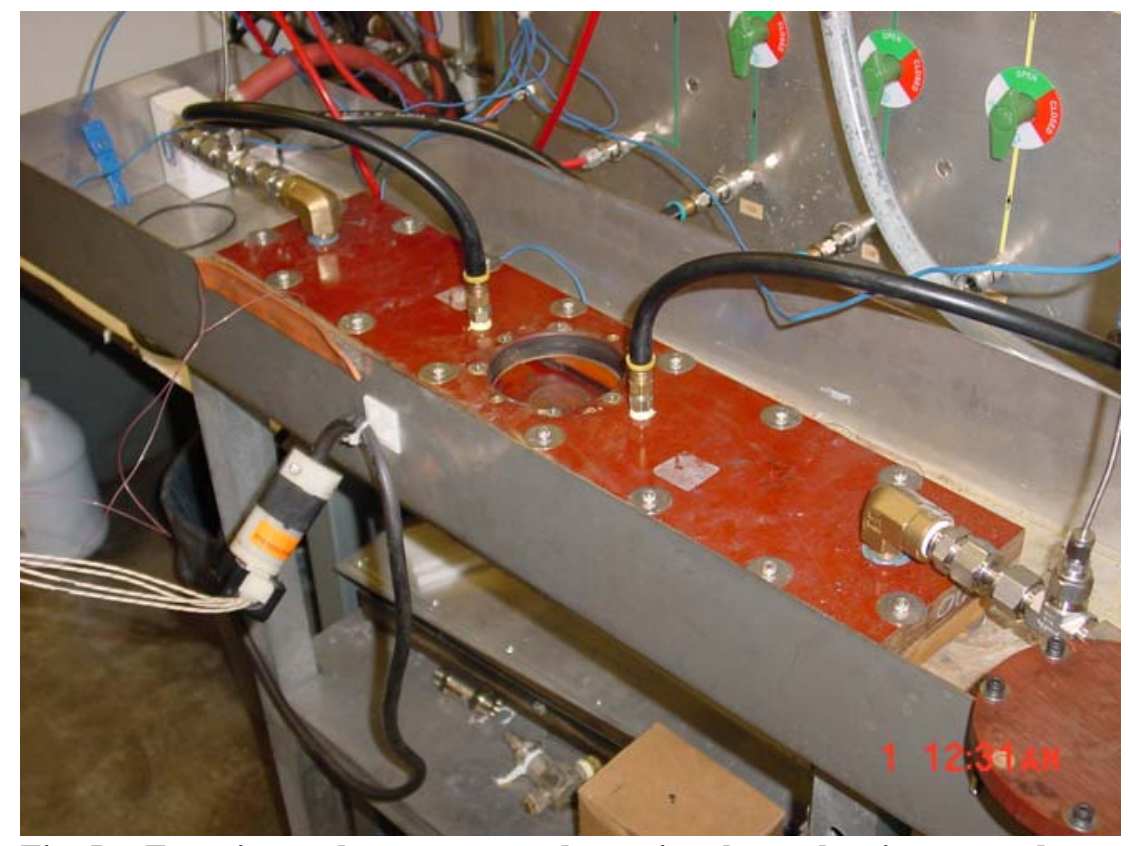

Fig. 5. Experimental apparatus to determine thermal resistance and permeability.

The permeability, $\kappa$, is an empirical constant determined from

$$
-\frac{d P}{d x}=\frac{\mu}{\kappa} U+\frac{C_{f}}{\sqrt{\kappa}} \rho U^{2}
$$

where

$$
\begin{aligned}
& P=\text { Pressure }(\mathrm{Pa}) \\
& x=\text { flow length }(\mathrm{m}) \\
& \mu=\operatorname{dynamic} \text { viscosity }(\mathrm{kg} / \mathrm{m} \cdot \mathrm{s}) \\
& \kappa=\text { permeability }\left(\mathrm{m}^{2}\right)
\end{aligned}
$$




$$
\begin{aligned}
& C_{f}=\text { Forcheimer Coefficient } \\
& \rho=\text { density }\left(\mathrm{kg} / \mathrm{m}^{3}\right) \\
& U=\text { fluid velocity in pores }(\mathrm{m} / \mathrm{s}) \text {. }
\end{aligned}
$$

The estimated form drag coefficients are given by [1].

$$
-\frac{d P}{d x}=\frac{\mu}{\kappa} U+\frac{C_{f}}{\sqrt{\kappa}} \rho U^{2}=A_{d r a g} \mu \frac{\left(1-V_{f}\right)^{2}}{V_{f}^{2}} U+B_{d r a g} \rho \frac{1-V_{f}}{V_{f}^{2}} U^{2}
$$

where $V_{f}=$ volume fraction of solid.

Thus, the A and B drag coefficients can be given as

$$
\frac{\mu}{\kappa}=A_{d r a g} \mu \frac{\left(1-V_{f}\right)^{2}}{V_{f}^{2}} \text { or } A_{d r a g}=\frac{V_{f}^{2}}{\kappa\left(1-V_{f}\right)^{2}}
$$

and

$$
\frac{C_{f}}{\sqrt{\kappa}} \rho=B_{d r a g} \rho \frac{1-V_{f}}{V_{f}^{2}} \text { or } B_{d r a g}=\frac{C_{f} V_{f}^{2}}{\sqrt{\kappa}\left(1-V_{f}\right)}
$$

The $\mathrm{j}$ factor and $\mathrm{f}$ factor were calculated with the following equations. First, the local heattransfer coefficient of the ligaments of the foam is given by Eq. (5). Because the heater is a constant heat flux surface, the arithmetic average air channel temperature is used rather than log mean temperature difference(LMTD).

The local heat-transfer coefficient is given by

$$
h_{\text {loc }}=\frac{\dot{m} C_{p}}{A_{\text {ligament }}} \frac{\left(T_{\text {out }}-T_{\text {in }}\right)}{\left(T_{\text {interface }}-\frac{1}{2}\left(T_{\text {out }}-T_{\text {in }}\right)\right)}
$$

where

$$
\begin{aligned}
& m=\text { mass velocity }(\mathrm{g} / \mathrm{s}), \\
& C_{\mathrm{p}}=\text { specific heat of air }(\mathrm{J} / \mathrm{g} \cdot \mathrm{K}), \\
& A_{\text {ligament }}=\text { total area of ligaments }\left(\mathrm{m}^{2}\right), \\
& T_{\text {out }}=\text { outlet temp of air }\left({ }^{\circ} \mathrm{C}\right), \\
& T_{\text {in }}=\text { inlet temp of air }\left({ }^{\circ} \mathrm{C}\right), \\
& T_{\text {interface }}=\text { interface temperature between foam and heater }\left({ }^{\circ} \mathrm{C}\right) .
\end{aligned}
$$

The $\mathrm{j}$ factor, $j$, is given by [2]

$$
j=\frac{h_{\text {ligament }}}{G C_{p}} \operatorname{Pr}^{2 / 3}
$$

The friction factor, $f$, is given by [2] 


$$
f=\frac{-\frac{d P}{d x} \sqrt{\kappa}}{\rho U^{2}}
$$

The form drag coefficients along with the area density (measured by mercury porosimetry) of $12,500 \mathrm{~m}^{2} / \mathrm{m}^{3}$ were used in Sect. 3.2 to develop the model of the foam heat transfer.

\subsubsection{Finned Foam Parameters}

Finned samples with varying fin gaps were machined from Koppers K-foam ${ }^{\circledR}$ L1 and from the ORNL experimental foam. The samples were machined with either constant-thickness fins $(0.03125$ in.) with a varying gap or constant fin gaps (0.05 in.) with a varying fin thickness (see Table 1 ).

Table 1. Foam sample dimensions

\begin{tabular}{ccc}
\hline Sample & Thickness, in. & Gap, in. \\
\hline \multicolumn{3}{c}{ Constant-thickness fins } \\
a & 0.03125 & 0.03 \\
b & 0.03125 & 0.04 \\
c & 0.03125 & 0.05 \\
d & 0.03125 & 0.06 \\
e & 0.03125 & 0.07 \\
f & Constant fin gap \\
f & 0.03 & 0.05 \\
g & 0.04 & 0.05 \\
h & 0.05 & 0.05 \\
i & 0.06 & 0.05 \\
j & 0.07 & 0.05 \\
\hline
\end{tabular}

The samples were placed in the flow rig and were tested as described in Sect. 3.1.1 and with the parameters calculated with the methods of Bejan [2], but using the fin surface area rather than the ligament surface area.

\subsection{TASK 1-B: MODELING DEVELOPMENT AND VALIDATION}

\subsubsection{New Model Development}

To develop the new CFD model using FLOW3D, a simple 3-D geometry representing the actual wind tunnel flow rig was designed with the program. Then the foam porosity, specific surface area, and $\mathrm{A}$ and $\mathrm{B}$ drag coefficients were input along with the foam thermal conductivity from one experimental run of the $\mathrm{L} 1$ foams as the foam variables. The simulation was run, and the results were compared with the measured experimental values. The A and B drag coefficients were used as fitting parameters to give an accurate representation of the experimental data.

\subsubsection{New Model Validation}

To validate the model, the fitted A and B drag coefficients were then used to model a finned foam sample. The predicted results were then compared with the experimental data to validate the new model. Accuracy of the predicted parameters to within 5\% of the experimental parameters is usually considered sufficient to validate a mathematical model. 


\section{RESULTS}

\subsection{TASK 1-C: PERMEABILITY MEASUREMENTS}

\subsubsection{Solid Foams}

Figure 6 reports the measured pressure drop vs the calculated pressure drop using Eq. (1) after the permeability was extracted from the data. Clearly, Eq. (1) represents the behavior of the foam well.

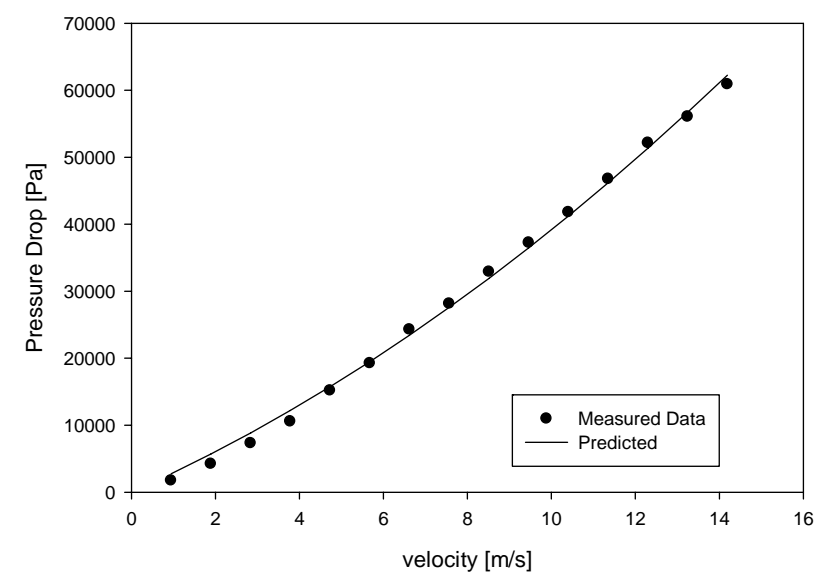

Fig. 6. Predicted vs measured pressure drop of the L1 foams.

The permeabilities of the commercial L1 foams and the experimental L1 foams from the measured data are given in Table 2.

Table 2. Foam permeabilities

\begin{tabular}{lcc}
\hline Foam sample & $\boldsymbol{\kappa}$ & $\mathbf{C}_{\boldsymbol{f}}$ \\
\hline L1 & $5.57 \mathrm{E}-09$ & 0.0070 \\
L1-exp & $5.64 \mathrm{E}-09$ & 0.0064 \\
\hline
\end{tabular}

It is evident that the experimental foams did not have a significant effect on the pressure drop behavior of the foam. From Table 2, the A and B drag coefficients were calculated to be 80E9 and 7205, respectively. These values were used in Sect. 3.2 to model the foam behavior.

\subsubsection{Finned Foams}

The finned foams were measured for both permeability (pressure drop) and heat transfer. As can be seen from the data in Table 3, the permeability of the foam with fins is more than three orders of magnitude $(1000 \times)$ greater than that of the solid foams. This should dramatically decrease the pumping power required to move the fluid, but it may not be useful in increasing the heat transfer.

Table 3. Comparision between solid foam and finned foam

\begin{tabular}{lcl}
\hline \multicolumn{1}{c}{ Foam sample } & \multicolumn{1}{c}{$\boldsymbol{\kappa}$} & \multicolumn{1}{c}{$\mathbf{C}_{\boldsymbol{f}}$} \\
\hline L1 & $5.57 \mathrm{E}-09$ & 0.0070 \\
L1-finned, 0.050 fin- 0.040 gap & $3.13 \mathrm{E}-06$ & 0.000018 \\
\hline
\end{tabular}




\subsection{HEAT-TRANSFER COEFFICIENTS}

\subsubsection{Solid Foams}

Following the calculation of the A and B drag coefficients, the $\mathrm{j}$ and $\mathrm{f}$ factors for the heat transfer of both the solid foams and the finned foams were calculated using the method described in Sect. 3.2. To understand the behavior of the flow in the foam structure, typically the factor and the $\mathrm{j}$ factor are correlated to the Reynolds number. To calculate the $\mathrm{j}$ factor, the heat transfer coefficient of the ligaments was used rather than the interface between the foam and the heater. This is to ensure that the characteristic length for both factors is consistent.

Figure 7 shows the calculated $\mathrm{j}$ and $\mathrm{f}$ values for both the commercial and experimental foams. Several things can be inferred from this plot. First, as expected, the friction factor is very linear with a negative slope. The $\mathrm{j}$ factor should be linear as well and should be roughly parallel to the friction factor.

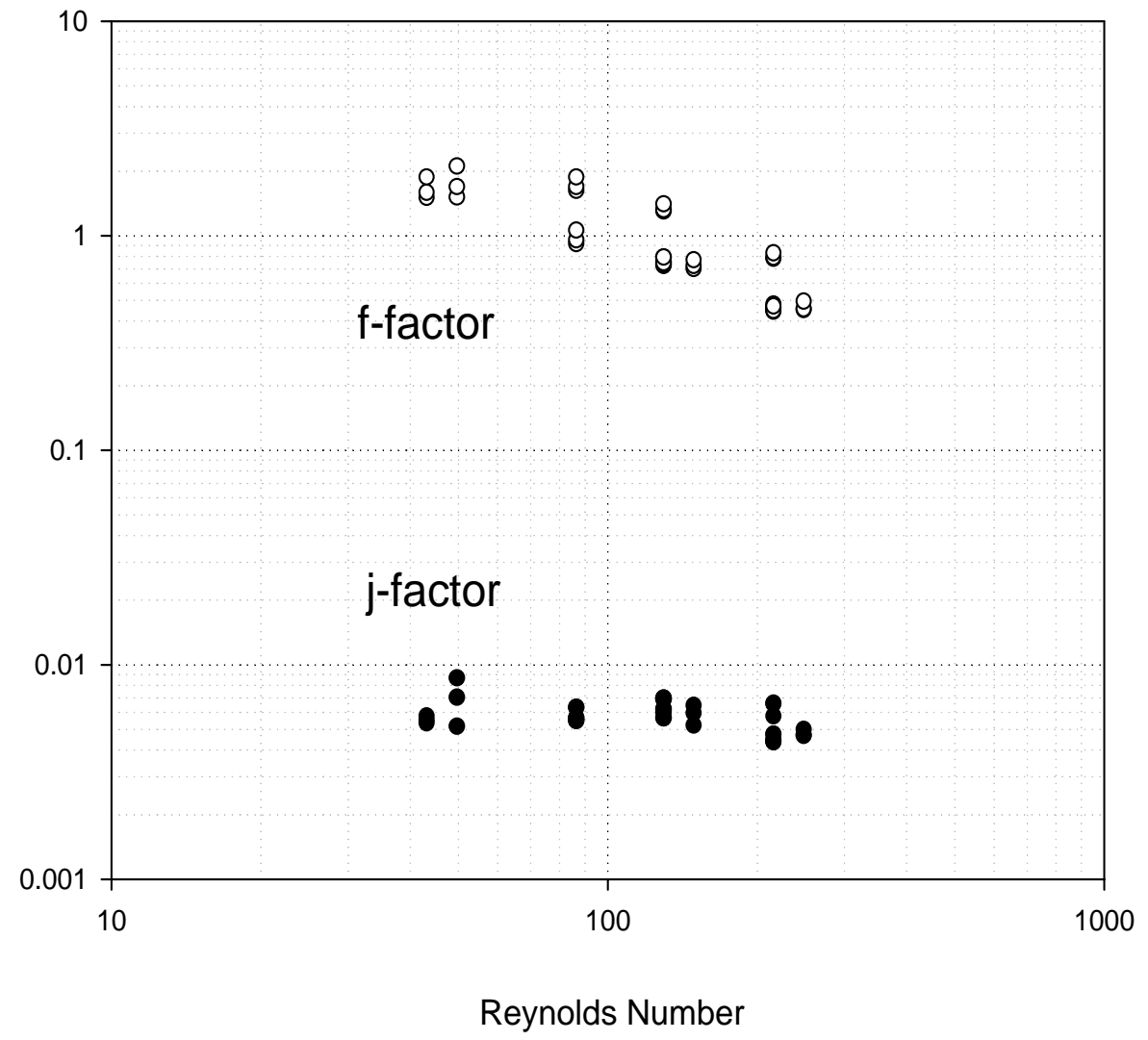

Fig. 7. The $\mathrm{j}$ and $\mathrm{f}$ factors vs Reynolds number for the solid foams.

Next, it is convenient to plot the $\mathrm{j} / \mathrm{f}$ ratio, which relates the heat transfer to the friction loss as an excellent method to determine the "goodness" of an enhanced heat exchanger surface design. The calculated values are reported in Fig. 8. As discussed in Cowell and Achaichia [4] the best j/f ratios demonstrated by state of the art heat exchangers are approximately 0.25 , whereas the best $\mathrm{j} / \mathrm{f}$ ratio for solid foam is about 0.015 . This is understandable as the foam has a very high pressure drop, thus a very high $\mathrm{f}$ factor. The Reynolds analogy value of 0.5 may be used to set an upper limit of this ratio (in effect, a perfect heat exchanger) and has yet to be demonstrated. 


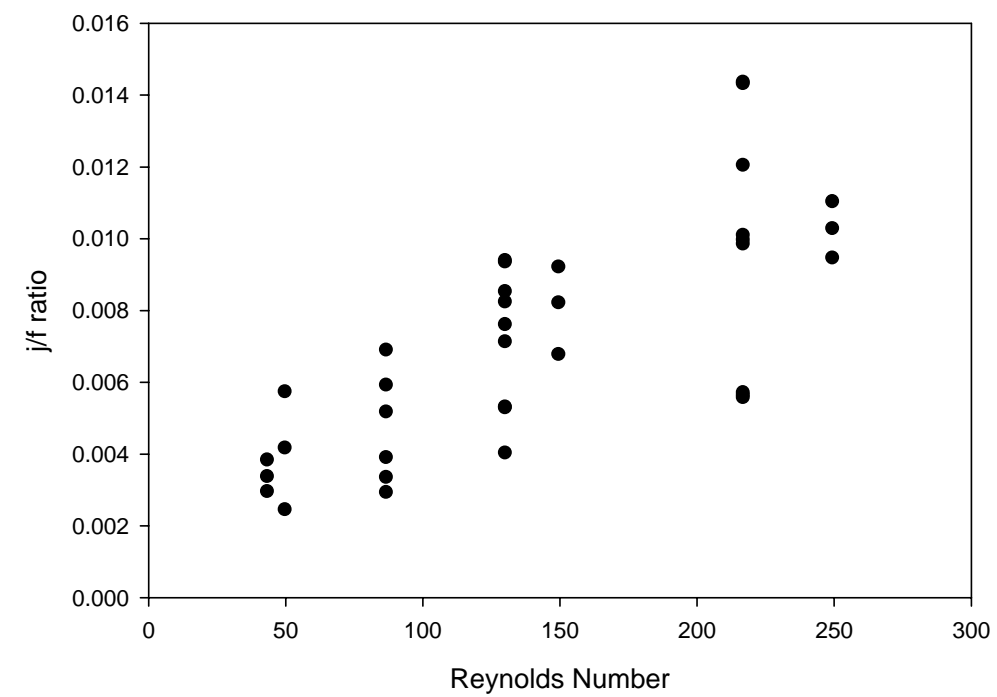

Fig. 8. Ratio of $\mathbf{j}$ to $f$ for the solid foams as a function of Reynolds number.

One very exciting fact is that the foam can be engineered to reduce pressure drop without affecting heat transfer. As previously discussed, the corrugated heat exchangers demonstrated a significant reduction in pumping power without affecting heat transfer. To get a better understanding of this, a previous test (not in this program) measured the $\mathrm{j}$ and $\mathrm{f}$ factors for the D1 foams from Koppers (a much denser foam with higher pressure drops) and then corrugated the actual tested foam sample and remeasured the "apparent" $\mathrm{j}$ and $\mathrm{f}$ factors. Figures 9 and 10 show this relationship. It is very exciting because it shows that the corrugations can increase the $j / f$ ratio significantly, although it may not be the same scaling with the L1 foams. As can be seen, corrugating the foams has the effect of reducing the heat-transfer flow length, while retaining the heat-transfer area.

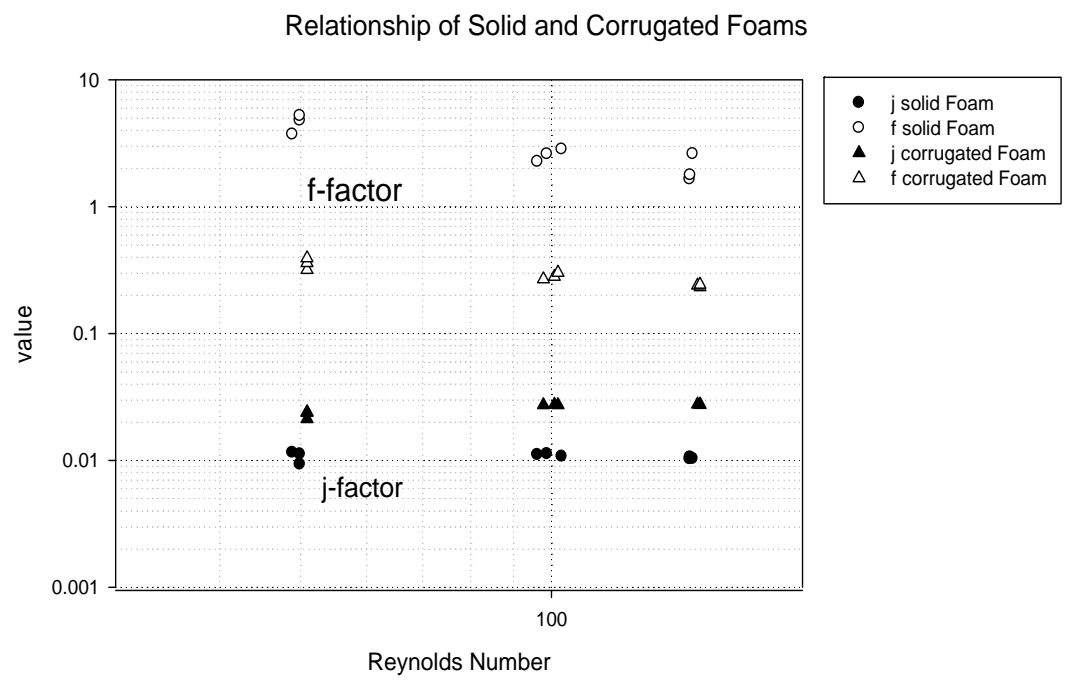

Fig. 9. Effect of corrugations on the heat-transfer characteristics of foams. 


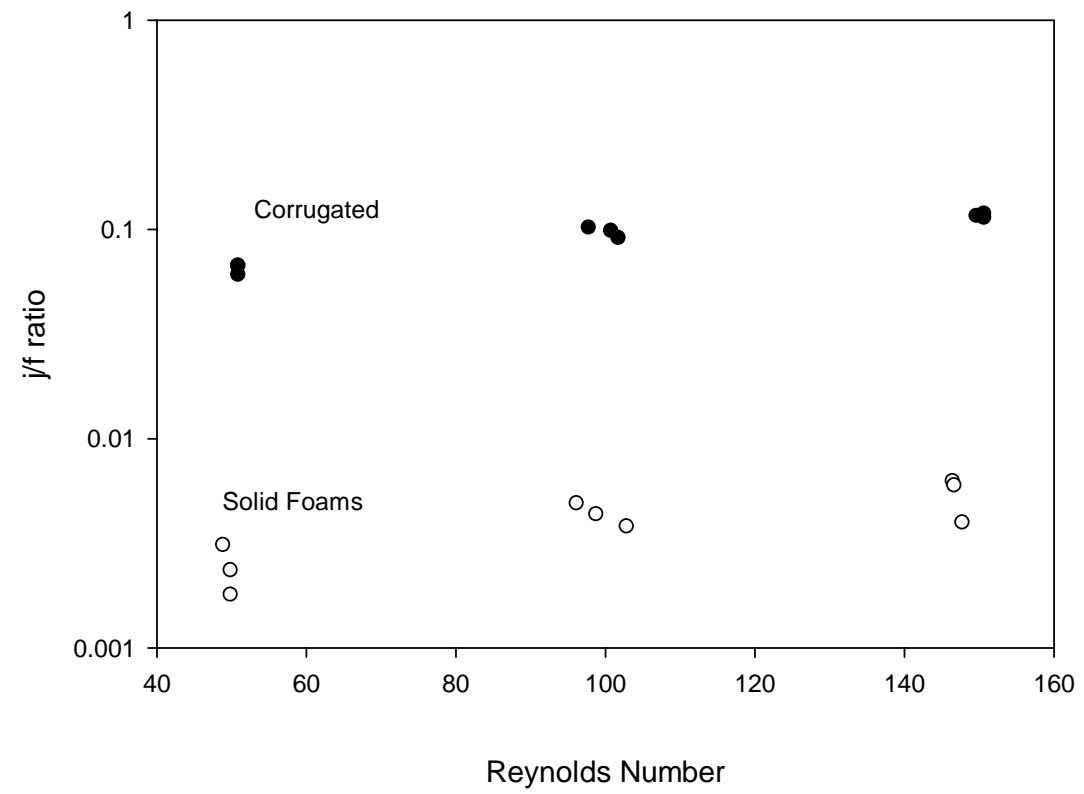

Fig. 10. Effects of corrugations on the $j / f$ ratio of solid foams.

From the data in Figs. 9 and 10, it is anticipated that corrugations of both the commercial L1 foams and the experimental L1 foams will result in an increase of the $\mathrm{j} / \mathrm{f}$ ratio to approach the 0.25 mark and be comparable to the $\mathrm{j} / \mathrm{f}$ of the state of the art heat exchangers. However, the biggest issue will not be $\mathrm{j} / \mathrm{f}$, but the absolute pressure that the system will require. This may be a potential drawback for the corrugated-foam design.

\subsubsection{Finned Foams}

The analysis from Sect. 4.2.1 was repeated for the finned foams to determine their heat-transfer coefficients and to determine whether a finned heat exchanger could be designed that has a lower pressure drop but the same effectiveness as the solid foams. Figure 11 shows the $\mathrm{j}$ and $\mathrm{f}$ factors for the series of samples having 0.03125 -in.-thick fins separated by varying gap widths. Significantly, the difference between $f$ and $j$ decreases as the fin gap decreases. This is more evident for the $j / f$ ratio (see Fig. 12). As shown by the figure, as the fin gap decreases, the ratio of $\mathrm{j}$ to $\mathrm{f}$ increases to above 0.1 . 


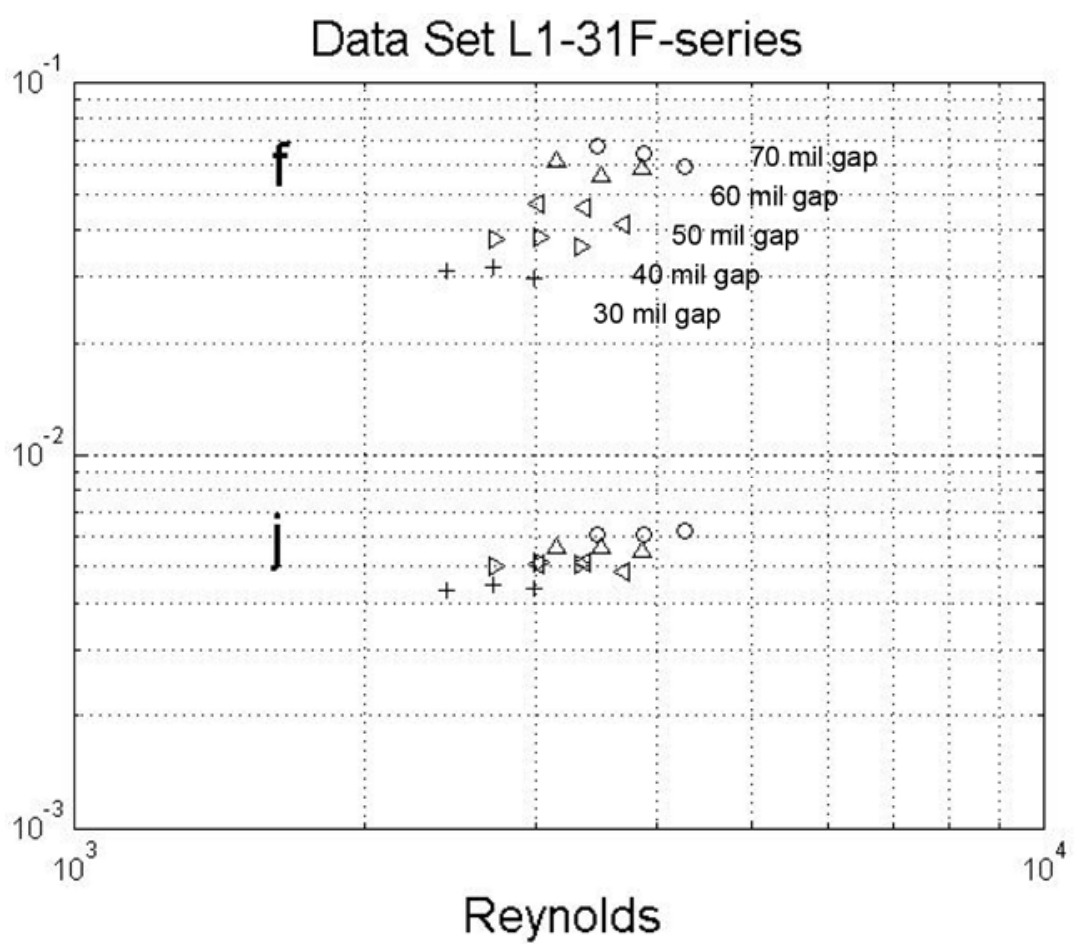

Fig. 11. The $f$ and $\mathbf{j}$ factors for the finned foams vs Reynolds number.

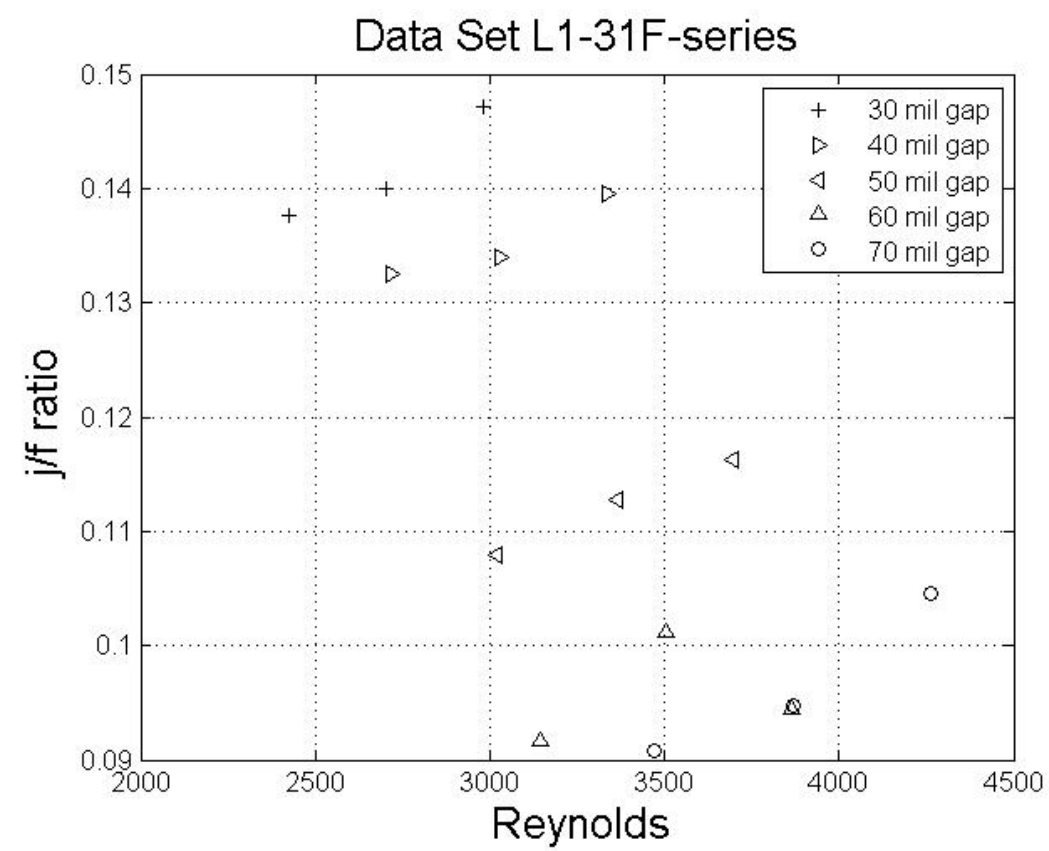

Fig. 12. Ratio of $j$ to $f$ for finned foams with constant fin thickness vs Reynolds number. 
The next set of experiments produced data for foam samples with constant fin gap of 0.050 in. and varying fin thicknesses. Figure 13 shows the $\mathrm{j}$ and $\mathrm{f}$ factors for several of the foams from this data set. Figure 13 shows a fall off of the $\mathrm{j}$ factor as the Reynolds number decreases, having a positive slope. This is common in cases when there are low flows and is indicative of measurement errors and other experimental artifacts. For example, at low flows, temperature stratification of the air flow makes it difficult to obtain true bulk air temperatures [3]. Currently, more data are being acquired at the higher Reynolds numbers to confirm this.

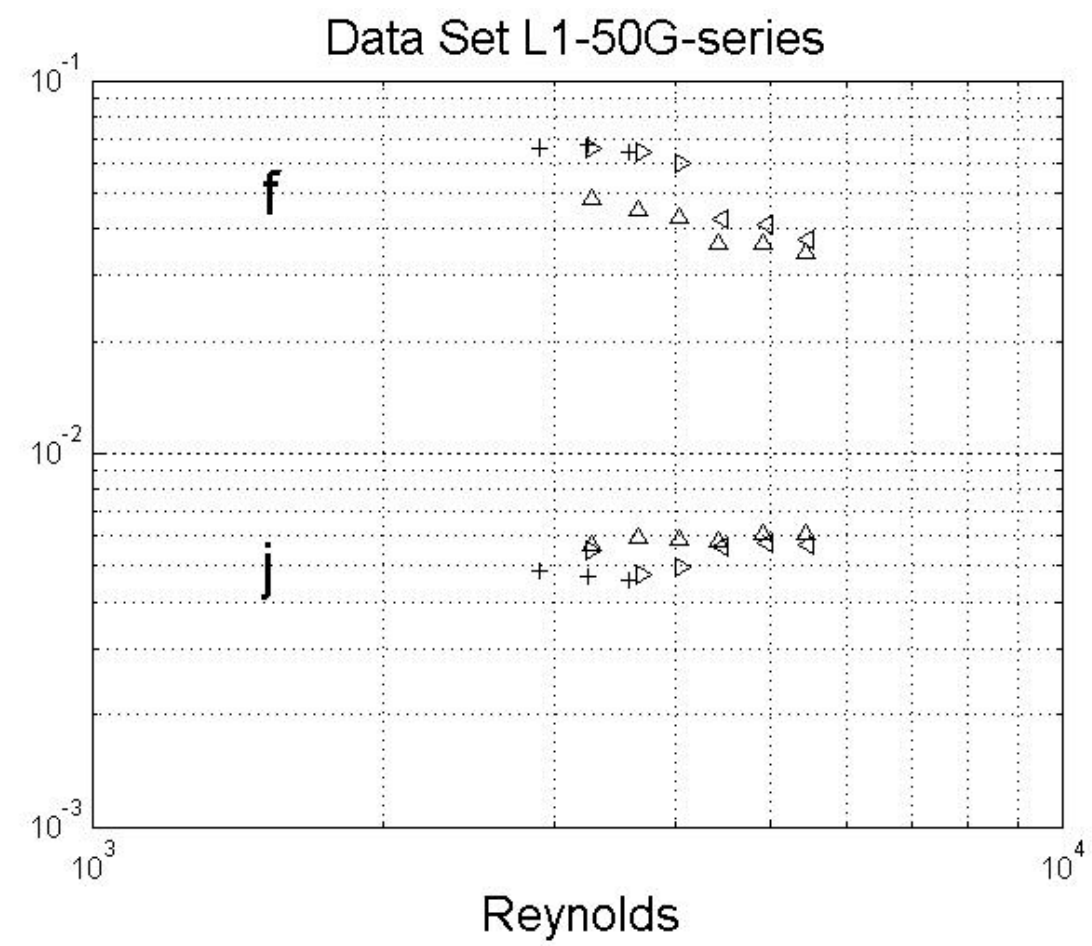

Fig. 13. Plot of the $j$ factor and the f factor of measured heat sinks with the graphite foam.

A very good indication of the effectiveness of the finned foam heat exchangers and their potential to compete with aluminum technology would be to plot the ratio of $\mathrm{j}$ to $\mathrm{f}$ vs the Reynolds number (see Fig. 14). As can be seen, there is a maximum near 0.18 , which is a very good number for initial tests on a heat exchanger design and is comparable to existing commercial heat exchangers. This indicates that with optimization, this number may improve and may exceed that of traditional heat exchangers. Additional thought is being given to the development of vortex generators within the fin gaps with the objective of increasing the heat transfer but not at the expense of higher pressure drops. 


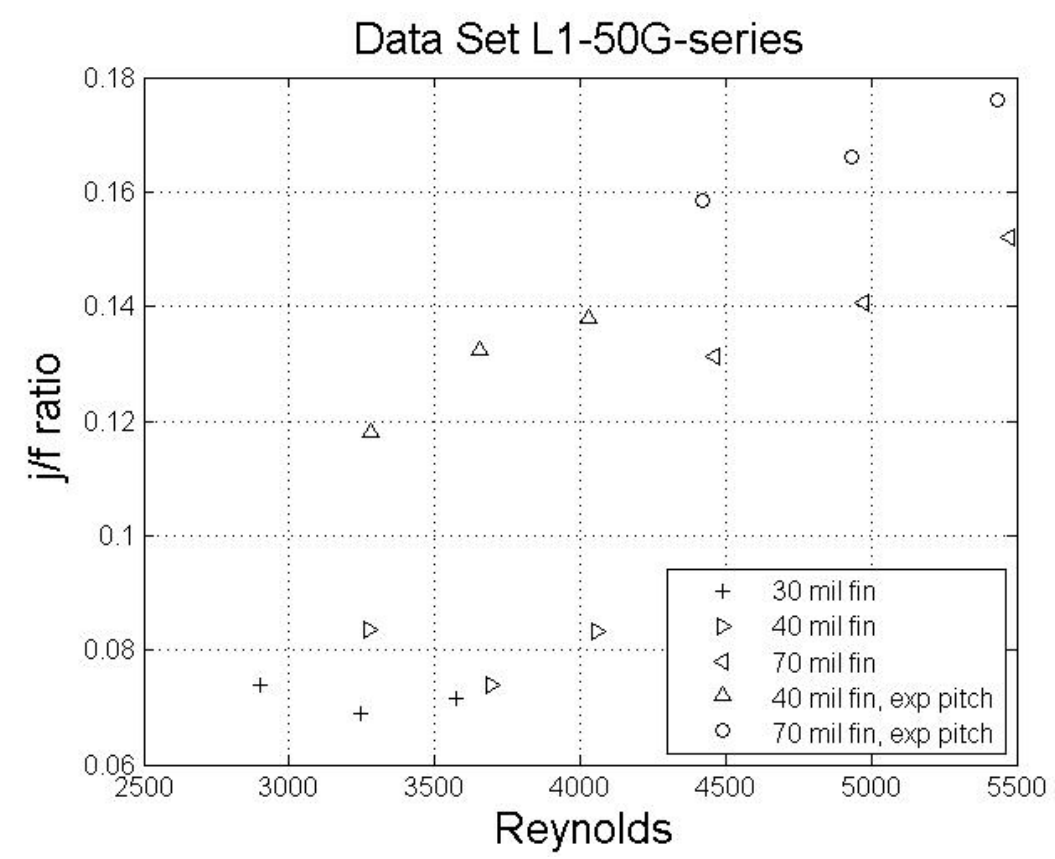

Fig. 14. Ratio of the $j$ factor to the $f$ factor vs the Reynolds number.

\subsection{MODELING RESULTS}

The CFD model required many iterations to determine the values of the drag coefficients A and B that correctly predicted the experimental data. The form drag coefficients were calculated from the permeability data and were used to simulate the foam in the model. As expected, the model predicted the pressure drop within $5 \%$ of the measured data based on these calculated values. Figure 15 shows the pressure profiles as well as the temperature profiles of the foam and the water in the model. These values are also within $5 \%$ of the measured values (labeled in the figure as well).

The measured value for the surface area of the pores in the foam (available for heat exchange) was $12,500 \mathrm{~m}^{2} / \mathrm{m}^{3}$. Using this value, the model was iterated with the local heat-transfer coefficient until the temperature profiles were similar to that measured (see Fig. 1). This final value was 12.5 $\mathrm{W} / \mathrm{m}^{2} \cdot \mathrm{K}$. 

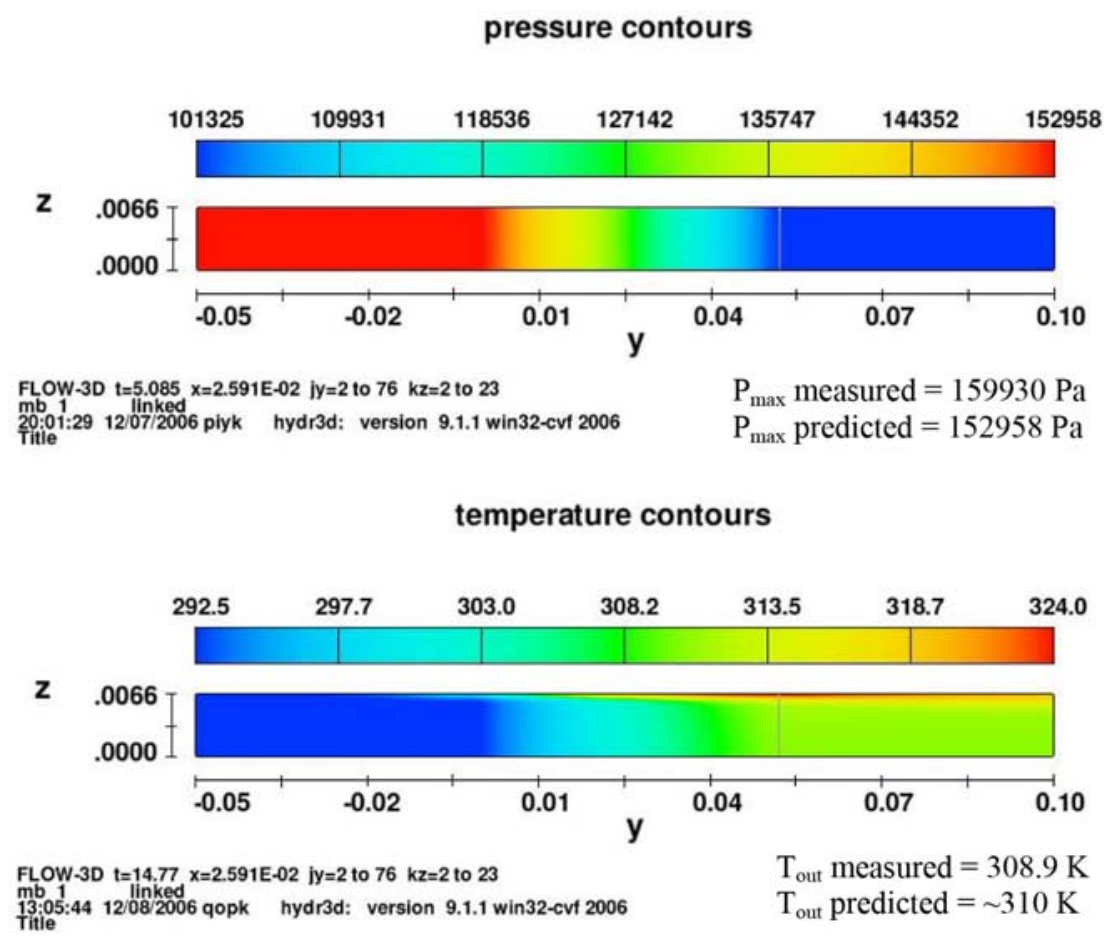

wall temperature contours

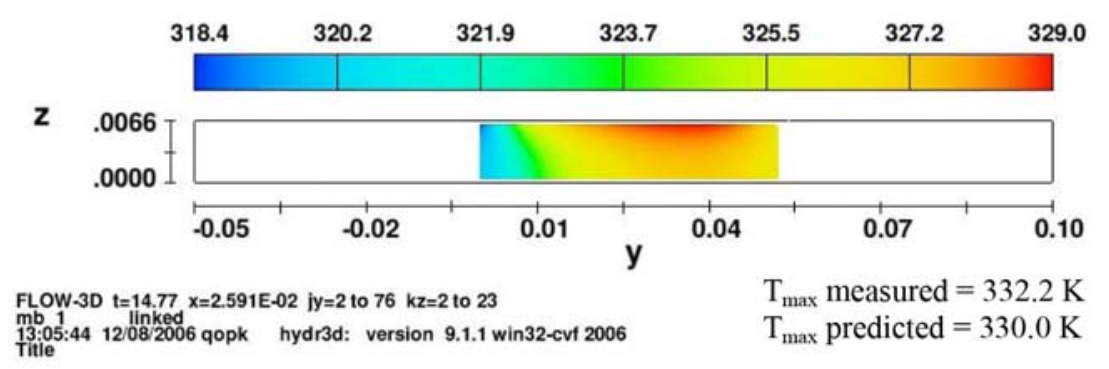

Fig. 15. Model results of the foam in the solid configuration.

\subsection{TASK 1-D: NEW MODEL VALIDATION}

After the solid foam characteristics were sufficiently understood, the model was used to predict the performance of the finned samples. Once calibrated, the FLOW3D model was used to analyze the finned heat exchanger design. For this model, a dimension of 50 mils on the fin thickness and 50 mils on the fin gaps were chosen. Figure 16 shows the 3-D model of the experimentally measured finned foam that was used in the FLOW3D program to model the heat transfer. Figure 17 shows the mesh arrangement for the finite volume model used by FLOW3D. 


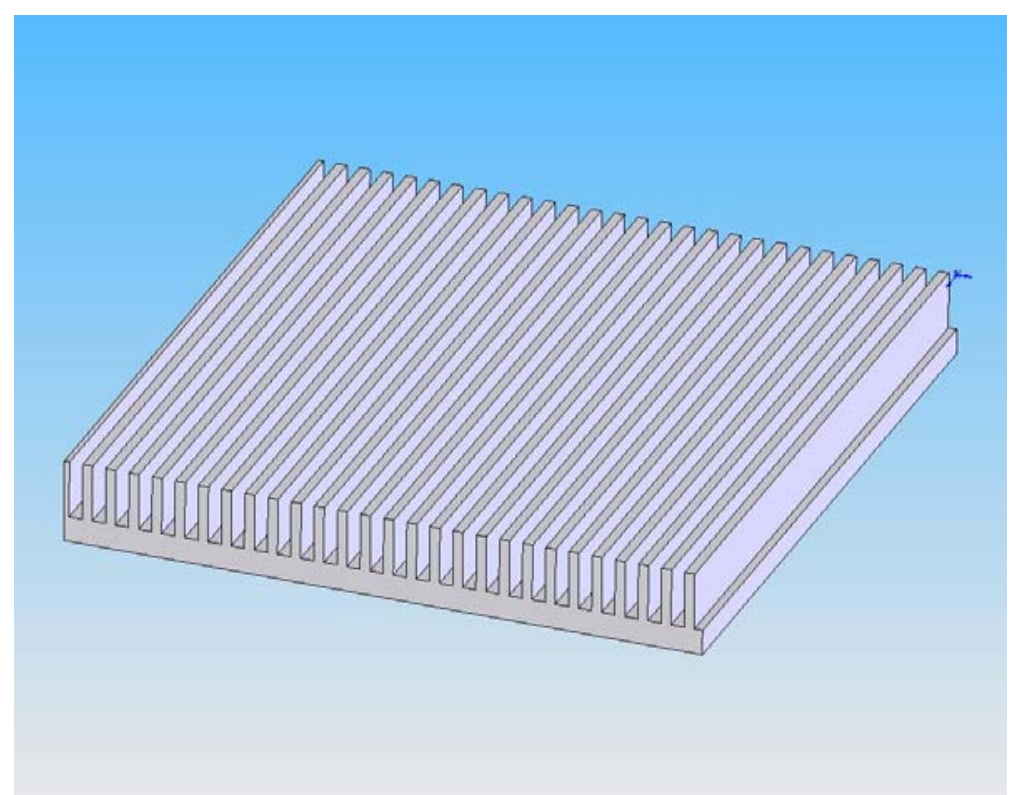

Fig. 16. Model heat sink to be used with FLOW3D CFD program.
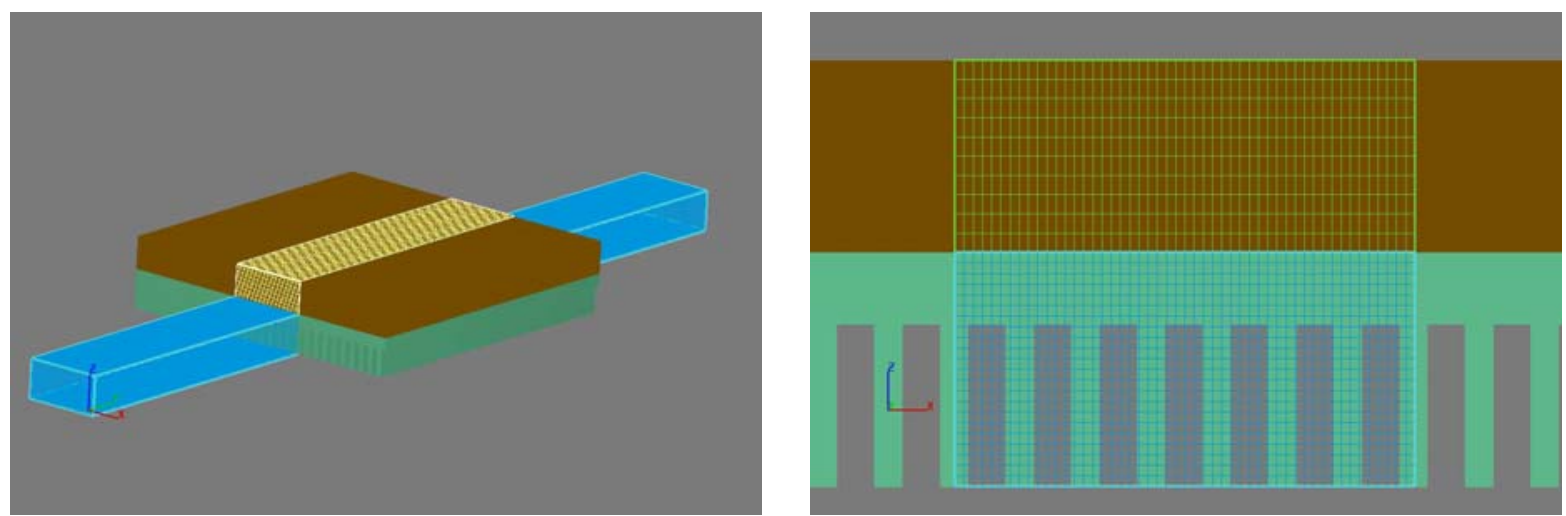

Fig. 17. Mesh for the model input of FLOW3D.

Figure 18 shows the results of the model and the velocity profiles through the foam fins.

Interestingly, Fig. 18 shows that flow occurs within the pores of the foam. This improves heat transfer above what was expected. Since the flows are collateral to main airflow, pressure drop was not increased significantly. This unexpected development offers the potential to further raise heat transfer in future designs by maximizing collateral flows with induced vortices or other engineered features. By including dimples, wavy structures, and vortex generators in the machined structures, heat transfer can be increased by inducing better contact of the air flow to the surfaces. Typically this will increase the friction drag but can actually reduce the overall pressure drag. (Surface configurations can allow a trade-off between friction drag and pressure drag. 


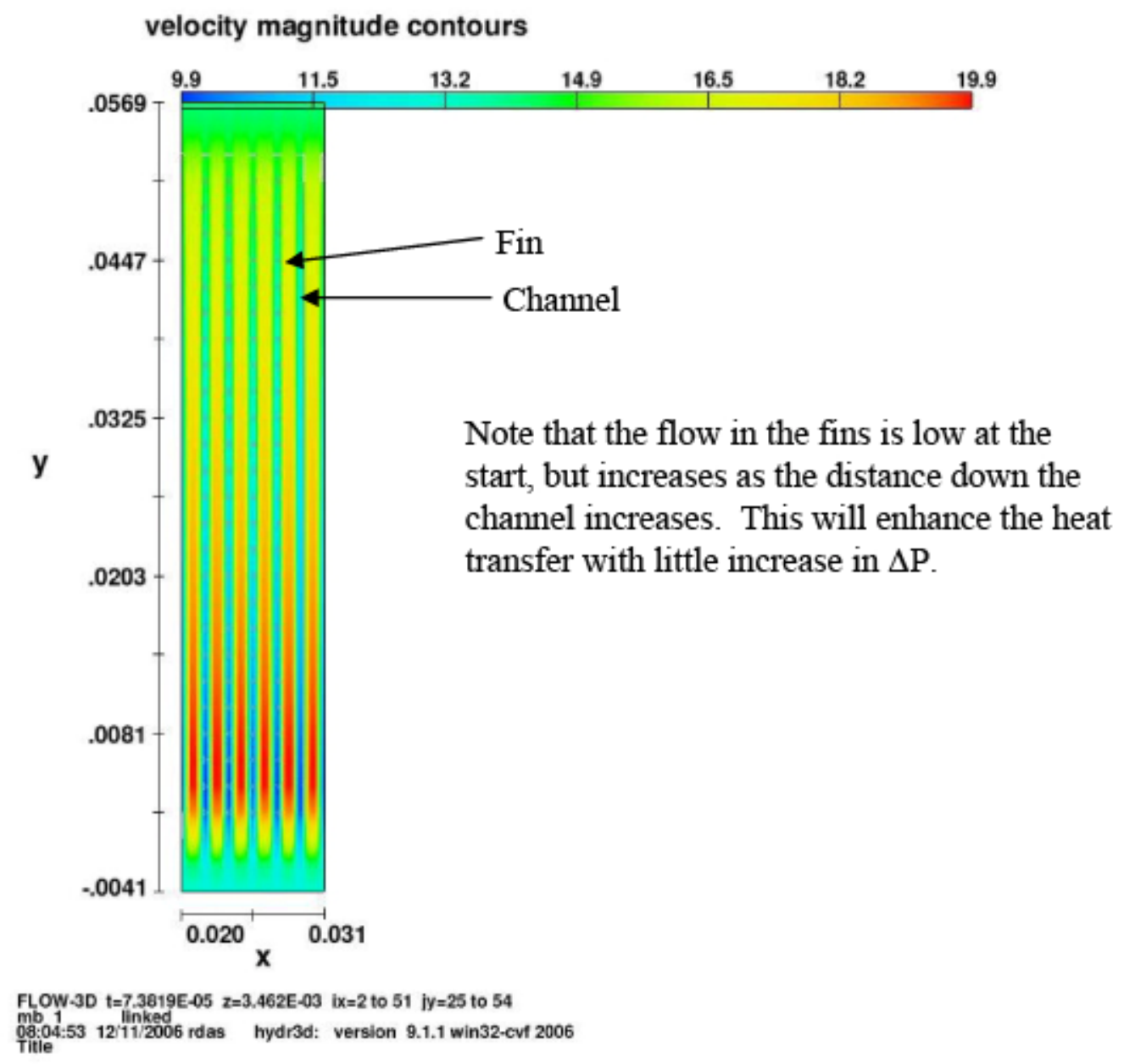

Fig. 18. Model results of the finned structures.

Figure 19 shows the temperature profiles through the foam model at two different modeled flow rates. The model of the finned structure correlates with the measured results. This indicates that the parameters determined in the solid flow-through configuration will extend to the finned flow-over configuration.

For the model, heat inputs of $12.5 \mathrm{~W}$ and $51 \mathrm{~W}$ were used in two different model runs. An air velocity of $4 \mathrm{~m} / \mathrm{s}$ was used, and the resulting models were attained. The temperature change of the air was $\sim 75 \%$ of that of the maximum temperature difference between the heat sink and the inlet air (approach temperature) in both cases (see Table 4). 

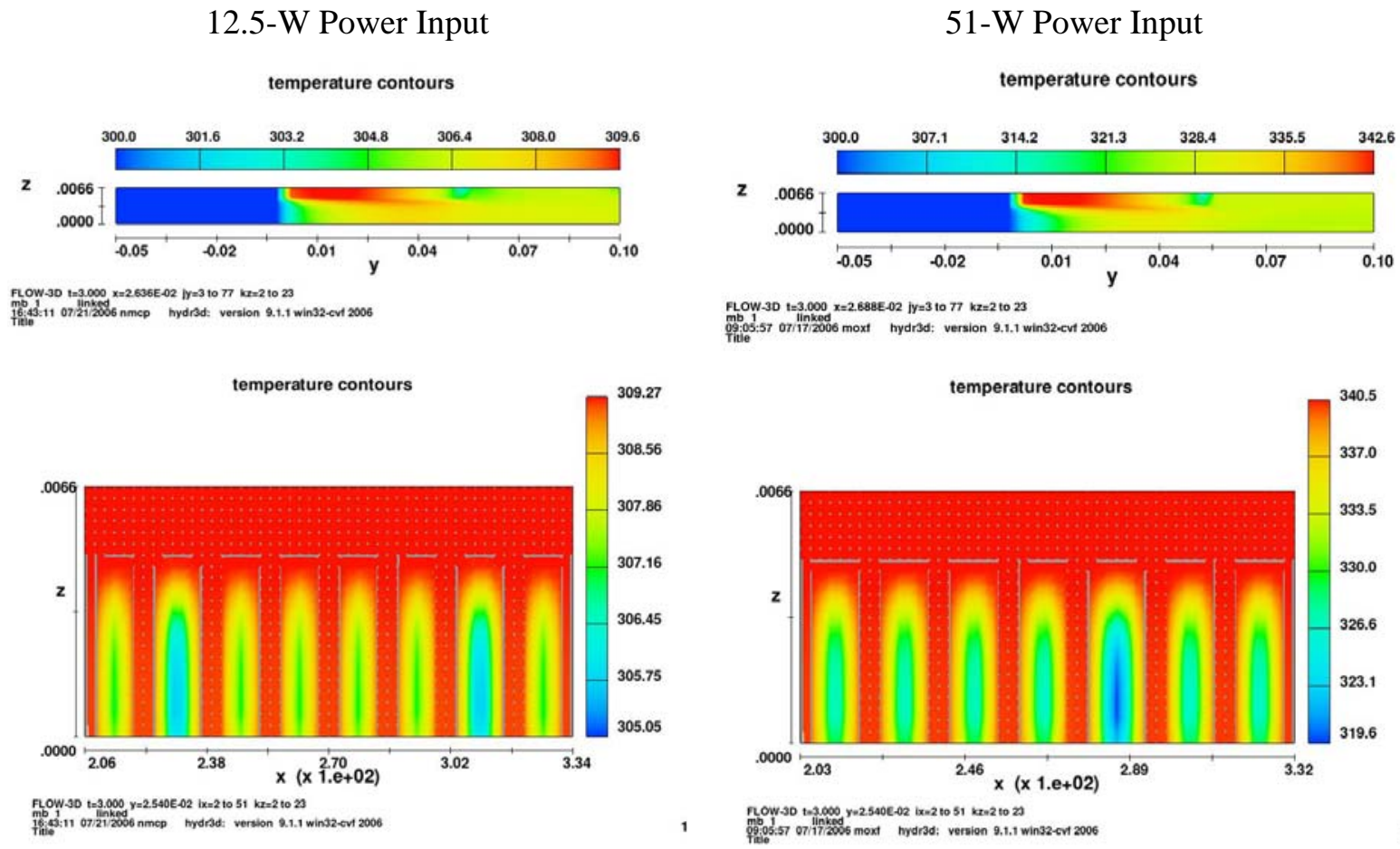

Fig. 19. Model results.

Table 4. Modeled results

Temperature

Power input (W)

12.551

\section{Run $1^{a}$}

Temperature rise of air $\left({ }^{\circ} \mathrm{C}\right) \quad 66$

Temperature rise above ambient of heat sink $\left({ }^{\circ} \mathrm{C}\right) \quad 8 \quad 35$

\section{Run $2^{b}$}

Temperature rise of air $\left({ }^{\circ} \mathrm{C}\right)$

$6.5 \quad 26.6$

Temperature rise above ambient of heat sink $\left({ }^{\circ} \mathrm{C}\right) \quad 13.9 \quad 60$

Thermal resistance of interface $\left(0.4^{\circ} \mathrm{C} / \mathrm{W}\right) \quad 5 \quad 20.4$

Actual temperature rise of sink above ambient $\left({ }^{\circ} \mathrm{C}\right) \quad 8.9 \quad 39.6$

${ }^{a}$ The temperature is measured at center of heat sink (not at the maximum temperature location).

${ }^{b}$ The measured temperature is higher than modeled temperature as the location for measuring includes a thermal resistance between the sink and the heat source. This was not modeled. The model was verified to give reasonable results. Another project at ORNL is further optimizing the model to give more accurate results. 


\section{CONCLUSIONS AND RECOMMENDATIONS}

\subsection{CONCLUSIONS}

It was found that the new CFD model using FLOW3D can predict both solid foam heat transfer and finned foam heat transfer with the validated model parameters. In addition, it was found that the finned foam structures exhibited $\mathrm{j} / \mathrm{f}$ ratios that indicate that significant heat transfer is occurring within the fin structures due to aerodynamically induced flow, which is not present in solid aluminum fin structures. It is possible that the foam surfaces can act as turbulators that increase heat transfer without affecting pressure drop, like the vortex generators seen in state of the art heat exchangers. These numbers indicate that the foam can be engineered into an excellent heat exchanger.

It was also found that corrugating the solid foams would increase the $j / f$ ratio dramatically, allowing the solid foams to compete directly with standard heat exchangers. Although corrugated L1 foam samples have not been produced (attempts are under way), it is possible that their $\mathrm{j} / \mathrm{f}$ ratio can be even higher than those of the finned structures.

\subsection{RECOMMENDATIONS}

The model was validated, and the heat-transfer calculations show that there is significant promise for developing heat exchangers with superior performance. Therefore, it is recommended that the funding for Phases 2 through 5 be approved so that designs can be pursued for solid foam heat exchangers, in which corrugated foams are used (Fig. 20), and for finned heat exchangers, in which tubes and round fin structures are used (Fig. 21).

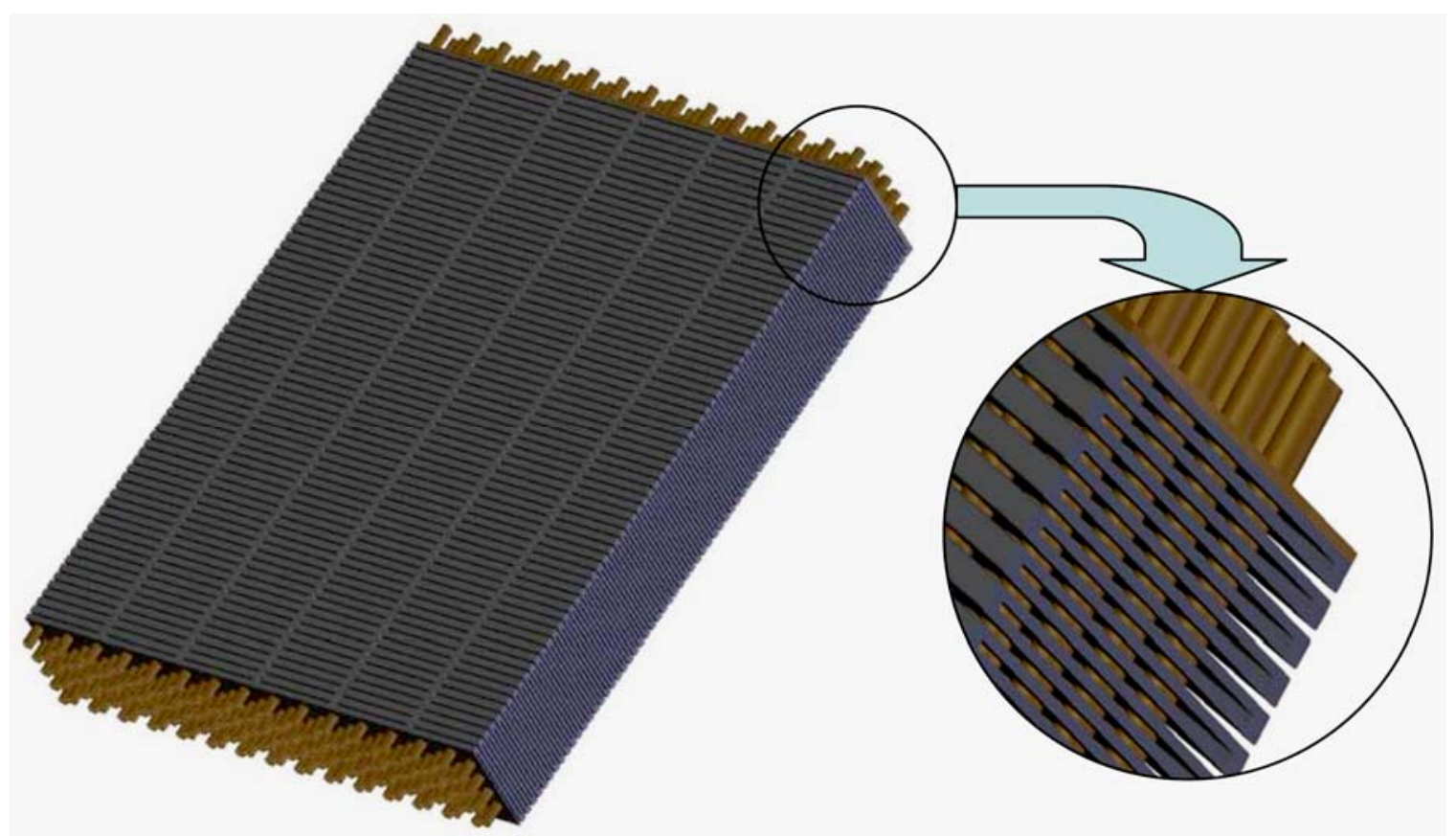

Fig. 20. Conceptual design with graphite foam in a corrugated array that forces air through the pores of the foam. A standard design would involve a filter in line with this heat exchanger to prevent fouling. 


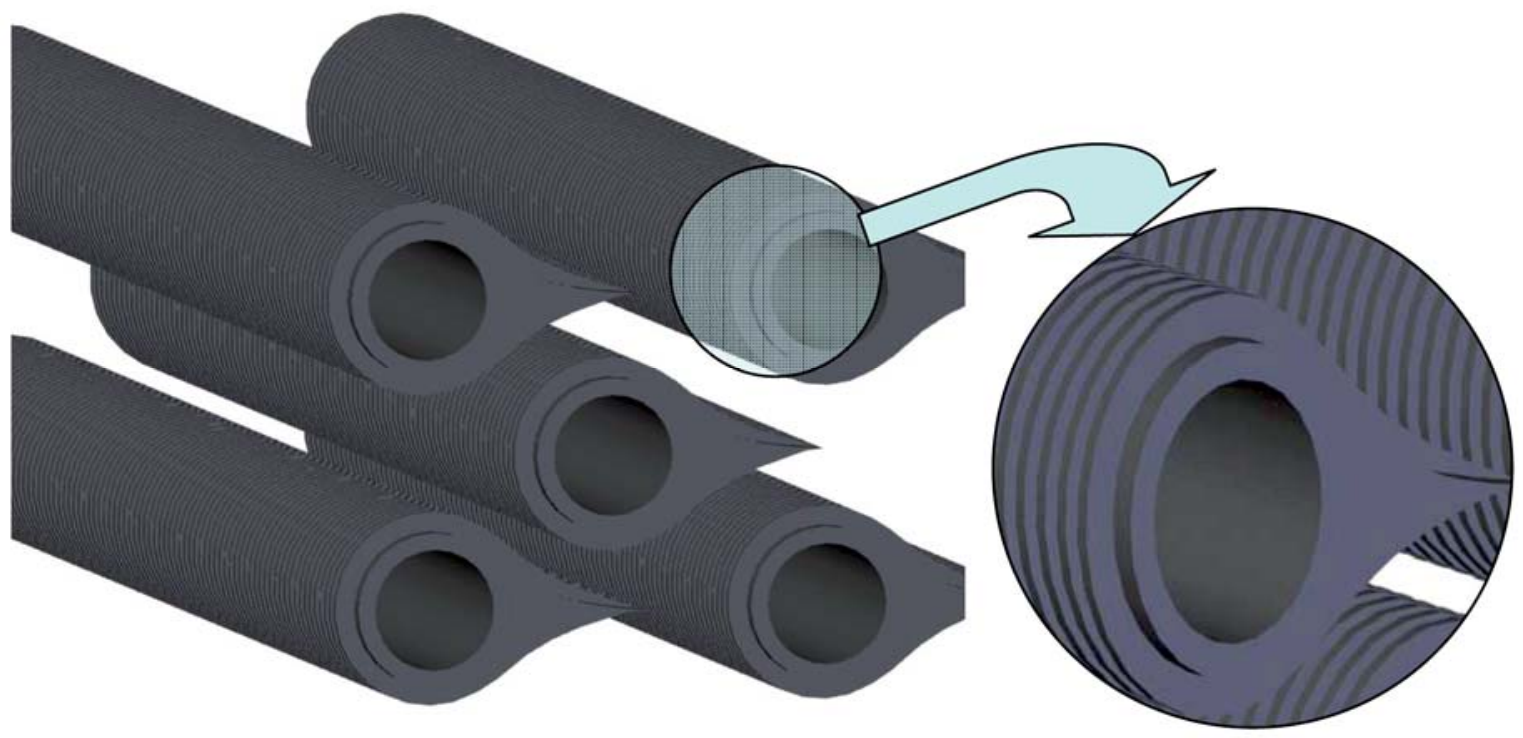

Fig. 21. Concept that uses airfoils with tubes to provide increased surface area and reduced pressure drops. The airfoil also protects the part of the foam through which air passes from the heavy particles in the air, thus minimizing fouling of the heat-transfer surface area. 


\section{REFERENCES}

1. Operating Manual, FLOW3D® CFD program, Flow Science, Santa Fe, New Mexico, 2006.

2. A. Bejan, Convection Heat Transfer, John Wiley, New York, 1984.

3. R. K. Shah and D. P. Sekulic, Fundamentals of Heat Exchanger Design, John Wiley, New York, 2003.

4. T. Cowell and N. Achaichia, "Compact Heat Exchangers in the Automobile Industry," Compact

Heart Exchangers for the Process Industries Proceedings, Snowbird, Utah, June 22-27, 1997, Begell House, 1997. 


\section{DISTRIBUTION}

1. James Klett

2. Jim Conklin

3-5. Richard Stouder

6. Pete Pappano

7. Tim Burchell
8-10. Mike Stoia, Boeing

11. Rick Gaeta, GTRI

11. ORNL Office of Technical Information and Classification 